\title{
Knowledge About and Health Practices on Sexually Transmitted Infections among Commercial Sex Workers in an Urban Community
}

\author{
Perry Paul J. Espinosa \\ Woosong College, Daejeon, Republic of Korea \\ paulespinosa721@gmail.com
}

\begin{abstract}
This study is a descriptive-relational research, determined the knowledge about sexually transmitted infections, knowledge on the services offered by the social hygiene clinic, and the health practices among commercial sex workers in an urban community. The respondents were knowledgeable about sexually transmitted infections specifically on the transmission, prevention, and the signs and symptoms of the disease. They also knew that the social hygiene clinic offers free consultation, one-on-one counseling, reading materials, and diagnostic tools. The respondents did not have correct promotive health practice, however, they had better preventive, curative, and rehabilitative measures. The relationship between the knowledge about sexually transmitted infections and knowledge on the services offered by the social hygiene clinic, and the health practices of the sex workers did not yield significant results. The findings suggest that a more comprehensive approach which provides a range of services to commercial sex workers including information dissemination, sexually transmitted infections promotive program, and health education should be sustained and strengthened.
\end{abstract}

Keywords: Sexually Transmitted Infections, Health Practices, Commercial Sex Workers, Knowledge about Sexually Transmitted Infections, Social Hygiene Clinic

\section{Introduction}

STDs, also known as sexually transmitted infections (STIs), are typically caused by bacteria or viruses and are passed from person to person during sexual contact with the penis, vagina, anus, or mouth (National Institutes of Health, 2017).

The spread of sexually transmitted infections (STIs) continue to increase despite various attempts to reduce mortality and morbidity. According to World Health Organization (2017), it is estimated that more than 1 million cases of sexually transmitted infections (STIs) are acquired every day worldwide.

Sexually transmitted infections (STIs) have a profound impact on sexual and reproductive health worldwide, and continue to cause a major burden of disease (WHO, 2015). In the Philippines, sexually transmitted infections (STIs) are a major cause of morbidity. Studies have shown a high prevalence of STIs, among commercial sex workers, with the prevalence rate of selected infections reaching more than 40 percent. Behavioral surveillance data indicate high prevalence of risky sexual behavior such as multiple sexual partners and non-condom use are among the high risk groups (Sentinel STI Etiologic Surveillance System, 2005 by the Unites States Agency for International Development).

Sex workers working in bars, clubs, and spa are at increased risk of sexually transmitted infections (STIs) (McGrath-Lone, Marsh, Hughes, \& Ward, 2014) especially

Received (November 15, 2017), Review Result (February 5, 2018), Accepted (February 10, 2018) 
those female sex workers due to their social vulnerability and factors associated with their work like a history of multiple sex partners, inconsistent condom use, and co-infection with other STIs (Verscheijden et al., 2015).

In Iloilo City, commercial sex workers have to undergo weekly examinations as mandated by City Ordinance 2002-237 and they have been offered free counseling and STIs prevention services by the Social Hygiene Clinic, however, cases of sexually transmitted infections (STIs) have continued to rise.

The need for effective prevention STIs remains a high priority, and has been achieved in diverse settings. Efforts to reduce STI prevalence among sex workers have concentrated on three areas of intervention such as increasing condom use between sex workers and their clients, improving identification and treatment of curable STIs, and reducing demand for commercial sex (largely by means of risk reduction messages targeting men) (Steen and Dallabetta, 2003).

Knowledge plays a vital role in early detection, prevention, and treatment of STIs. As those people who do not know the symptoms may fail to recognize their need and so may not seek help (Amu and Adegun, 2015).

Research on the knowledge about sexually transmitted infections, knowledge about the services offered by the social hygiene clinic, and the health practices among commercial sex workers has been relatively limited. Locally, no study has yet explored this area. Identification of these areas would provide better insight for the development of strategies and health services tailored to the needs of this population.

\section{Objective of the Study}

This study determined the knowledge about sexually transmitted infections, knowledge on the services offered by the social hygiene clinic, and the health practices among commercial sex workers in Iloilo City, Philippines.

\section{Significance of the Study}

The results could provide valuable information to commercial sex workers to improve their understanding of the sexually transmitted infections and to further improve their health practices, thus reducing cases and preventing sexually transmitted infections. This research could also provide the Department of Health and Social Hygiene Clinic, in the Philippines, the basis of the specific programs, seminars, and information campaign to focus on, in order to help prevent cases of sexually transmitted infections. This may also help health educators and nurses to collect and analyze data for the purpose of researching, designing, implementing, and evaluating programs of the Department of Health and Social Hygiene Clinic. The result of the present investigation may also serve as additional information to other researchers who may wish to conduct similar studies.

\section{Methodology}

This study is a descriptive-relational research, one-shot survey. The respondents of this investigation were the 11 males and the 157 female commercial sex workers registered in the Social Hygiene Clinic in Iloilo City, Philippines.

The study has used a researcher-made questionnaire-checklist on the knowledge about sexually transmitted infections, knowledge on the services offered by the social hygiene clinic, and the health practices among commercial sex workers. The information provided is treated with utmost confidentiality and used solely for research. Data gathered were processed and analyzed using the Statistical Package for Social Sciences (SPSS) version 17. Level of significance was set at .05. 


\section{Profile of the Respondents}

The respondents of this study are described in terms of their age, sex highest educational attiring, civil status, work experience, and history of STD (STI). The data are shown in Table 1.

Age and Sex. Majority (70.80\%) of the 168 respondents included in this study were below twenty-four years old. Less than one-third (29.2 percent) were noted to be above twenty-five years old. The mean age was 24.53.

Highest Educational Attainment. The data show that majority of the respondents have attained high school education $(56.5 \%)$ while a little less than one-fifths were college and elementary educated (19.0\% and $15.5 \%$, respectively).

Civil Status. Majority of the respondents were single $(76.8 \%)$ while less than onefourth $(23.20 \%)$ were married. The data indicate that there were more single than married respondents.

Work Experience. The data further reveal that majority (74.4\%) of the respondents had less than three years work experience while only 25.6 percent had more than three years work experience.

History of STD (STI). The data show that majority had no history of STD (STI) $(87.5 \%)$ while only $13.5 \%$ had history of STD (STI).

Table 1. Distribution of Respondents According to Age, Sex, Highest Educational Attainment, Civil Status, Work Experience, and History of STD (STI)

\begin{tabular}{lll}
\hline Profile & Frequency & Percentage \\
\hline $\begin{array}{l}\text { I. Entire Group } \\
\text { II. Age }\end{array}$ & $\mathbf{1 6 8}$ & $\mathbf{1 0 0 . 0}$ \\
24 years old and below & 119 & 70.8 \\
25 years old and above & 49 & 29.2 \\
$\quad$ Total & $\mathbf{1 6 8}$ & $\mathbf{1 0 0 . 0}$ \\
III. Sex & & \\
$\quad$ Male & 11 & 6.50 \\
$\quad$ Female & 157 & 93.50 \\
$\quad$ Total & $\mathbf{1 6 8}$ & $\mathbf{1 0 0 . 0}$ \\
IV. Educational Attainment & & \\
$\quad$ Elementary Level & 26 & 15.50 \\
$\quad$ High School Level & 110 & 56.50 \\
$\quad$ College Level & 32 & 19.00 \\
$\quad$ Total & $\mathbf{1 6 8}$ & $\mathbf{1 0 0 . 0}$ \\
V. Civil Status & & \\
$\quad$ Single & 129 & $\mathbf{7 6 . 8 0}$ \\
$\quad$ Married \\
$\quad$ Total & 39 & 23.20 \\
VI. Work Experience & $\mathbf{1 6 8}$ & $\mathbf{1 0 0 . 0}$ \\
$\quad$ Less than 3 years & & \\
$\quad$ More than 3 years & 125 & 74.4 \\
$\quad$ Total & 43 & 25.6 \\
VII. History of STD (STI) & $\mathbf{1 6 8}$ & $\mathbf{1 0 0 . 0}$ \\
$\quad$ None & & \\
$\quad$ With STI & 148 & 87.5 \\
$\quad$ Total & 20 & 13.5 \\
$\quad$ & $\mathbf{1 6 8}$ & $\mathbf{1 0 0 . 0}$ \\
\hline
\end{tabular}




\section{Results and Discussions}

\section{Knowledge about Sexually Transmitted Infections}

Table 2 shows that majority of the respondents were aware that STIs are diseases that can be transmitted from one person to another through sexual contact (94.6\%). Eightyone percent of the respondents knew STIs could be prevented through safe sex practices and were aware of the signs and symptoms of STIs (80.4\%). On the other hand, less than one half of the respondents knew that STIs can be treated and multiple sexual partners could increase risk of developing STIs.

The result is consistent with the findings of Blay (2013) and Çalıkoğlu, Bilgeyerli and Koşan (2017) that majority of female porters in Madina knew the labelled signs and symptoms of STIs and more than one half of the brothel workers in Turkey knew that gonorrhea and syphilis can be cured by medications (Çalıkoğlu, Bilgeyerli, \& Koşan, 2017). Contrary to the results of the study, Sekoni, Odukoya, Onajole, and Odeyemi (2013) and de Matos, et al (2013) have found that the knowledge of sexually transmitted infections among sex workers in Nigeria and in Central Brazil were poor. Only 13.9 percent were aware that sexually transmitted infections could be asymptomatic and over one-third were not able to describe the signs and symptoms of sexually transmitted diseases.

\section{Table 2. Distribution of Respondents According to Knowledge about Sexually Transmitted Infections}

\begin{tabular}{|c|c|c|c|}
\hline $\begin{array}{l}\text { Knowledge About Specific Aspect } \\
\text { of STIs }\end{array}$ & $\begin{array}{l}\text { Correct } \\
\text { Answer }\end{array}$ & $\begin{array}{l}\text { Number of } \\
\text { Respondents } \\
\text { Who Got the } \\
\text { Correct } \\
\text { Answer } \\
(\mathrm{N}=168)\end{array}$ & $\begin{array}{l}\text { Percentage } \\
(\mathbf{1 0 0 \% )}\end{array}$ \\
\hline $\begin{array}{l}\text { 1. STIs are diseases that can } \\
\text { be transmitted from one person to } \\
\text { another through sexual contact. }\end{array}$ & Yes & 159 & 94.6 \\
\hline $\begin{array}{l}\text { 2. STIs can be prevented } \\
\text { through safe sex practices. }\end{array}$ & Yes & 136 & 81.0 \\
\hline $\begin{array}{l}\text { 3. Itchiness, pain upon } \\
\text { urination, and passage of pus in the } \\
\text { genitalia are some of the } \\
\text { manifestations of STIs. }\end{array}$ & Yes & 135 & 80.4 \\
\hline 4. $\quad$ STIs cannot be treated. & No & 70 & 41.7 \\
\hline $\begin{array}{l}\text { 5. Multiple sexual partners } \\
\text { can decrease risk to develop STIs. }\end{array}$ & No & 70 & 41.7 \\
\hline
\end{tabular}

\section{Knowledge on the Services offered by the Social Hygiene Clinic}

Table 3 shows that majority of the respondents were familiar with the services offered by the Social Hygiene Clinic. Almost all of them have information regarding free consultation (96.4\%) and the clinic offers one-on-one counseling (94.0\%). They were also aware that reading materials about STIs were provided by the clinic $(92.9 \%)$ and diagnostic tools to detect STIs were also available (78.6\%). Only 58.3 percent knew about free orientation and seminar on STIs. 


\section{Table 3. Distribution of Respondents According to Knowledge on the Services offered by the Social Hygiene Clinic}

$\begin{array}{ll}\text { Knowledge on the Services offered by the Correct Answer } & \text { Number of Percentage } \\ \text { Social Hygiene Clinic } & \text { Respondents Who (100\%) } \\ & \text { Got the Correct } \\ & \text { Answer (N=168) }\end{array}$

\begin{tabular}{|c|c|c|c|c|}
\hline 1. & Free consultation & Yes & 162 & 96.4 \\
\hline 2. & One-on-one counseling & Yes & 158 & 94.0 \\
\hline 3. & Reading materials about STD & Yes & 156 & 92.9 \\
\hline (STIs) & & Yes & 132 & 78.6 \\
\hline $\begin{array}{l}4 . \\
\text { (Gram S } \\
5 .\end{array}$ & $\begin{array}{l}\text { Diagnostic tools to detect STD } \\
\text { Staining, RPR, and VDRL). } \\
\text { Free orientation and seminar }\end{array}$ & Yes & 98 & 58.3 \\
\hline
\end{tabular}

\section{Health Practices of Commercial Sex Workers}

Table 4 presents the data on the number of correct health practices of the respondents. The items were divided into four categories namely, promotive, preventive, curative, and rehabilitative.

Promotive Practice. The date reveal that majority of the respondents did not have correct promotive practice. Only 54.8 percent of them had attended lecture-discussions, meetings, and seminars about sexually transmitted infections while less than one-half of them asked information on the transmission, prevention, and control of STIs (44.6\%) and discusses STIs issue with co-workers about its dangers (44.6\%). Moreover, only 41.1 percent had read updated guidelines that provide strategies to prevent STIs. However, less than one-third had read magazines, journals, and leaflets to be aware of STIs issue $(30.4 \%)$. The results further reveal that the respondents have a high probability of acquiring sexually transmitted infections because they do not have correct promotive practice.

Preventive Practice. In the preventive aspect, a small majority of the respondents, practice each of the preventive measures. Most of them had visited the doctor regularly and attentively listen to recommendations $(71.4 \%)$. A small difference noted on bathing immediately after sexual contact $(67.9 \%)$ and the use of condom by convincing and helping client to use it $(66.7 \%)$. It is quite good to note that a majority $(60.5 \%)$ of the respondents refused to work with the client who will not use condom. Less than one-half of the respondents used antibacterial soap, spermicide, foam, and vaginal wash before and after engaging in sexual activity (48.2\%).

The result is higher than that of Hosain and Chatterjee (2005) that only one-third of sex acts on the last day of work were protected through condom use among sex workers in Bangladesh. Furthermore, the result is supported by the findings of Coma Auli, MejíaLancheros, Berenguera, \& Pujol-Ribera (2015) where commercial sex workers aware of the higher risk of STI associated with their occupation. They identified condoms as the best preventive method and used them during intercourse with clients. They also implemented other preventive behaviors such as personal hygiene after intercourse. Control of sexual services provided, health education and healthcare services had a positive effect on decreasing exposure and better management of STIs/HIV.

Curative Practice. In the curative aspect, almost all of the respondents had correct curative measures. It was noted that there was a marked increase in the percentage on the use and taking religiously of clients with prescribed medications $(80.0 \%)$. The same 
percentage were noted in respondents who subjected self for laboratory test as recommended by the doctor (75.0\%) and stop from work if they feel signs and symptoms of STIs $(75.0 \%)$. Moreover, majority of them consulted and visited if there are signs and symptoms of infection $(65.0 \%)$ and visited the doctor immediately after engaging in unsafe sex $(60.0 \%)$.

The results is consistent with the findings of Adeneye, Mafe, Adeneye, \& Adeiga (2016) that good health seeking behavior was exhibited by respondents as most sought diagnosis and treatment for past STIs from medical doctors and majority of them reported that they subject themselves to periodical medical examinations.

Rehabilitative Practice. In this area, result show that most of them have correct rehabilitative practice. It can be noted that three-fourths of them $(75.0 \%)$ had allowed self to be confined for infection treatment. In fact, they were likely to join support groups in the prevention of STD (75.0\%). An equal percentage (70.0\%) were noted on following doctors' recommendations, seeking immediate healthcare, and abstaining from sexual activity during infectious stage of STIs $(70.0 \%, 70.0 \%$, and $70.0 \%$, respectively).

Table 4. Distribution of Respondents According to Health Practices

\begin{tabular}{ll}
\hline Health Practices & Number of Percentage \\
& Respondents $(100 \%)$ \\
Who Practiced \\
Correct Hygiene \\
$(\mathbf{N = 1 6 8 )}$
\end{tabular}

\section{Promotive}

1. Attend lecture-discussions, meetings, and seminars about STIs. 92

2. Discuss STIs issue to co-workers about its danger. 75

3. Ask information on the transmission, prevention, and control of 75

4. Read updated guidelines that provide strategies.

5. Read magazines, journals, and leaflets.

\section{Preventive}

1. Visit the doctor regularly.

2. Take a bath immediately after sex.

3. Convincing client to use condom.

4. Use of antibacterial soap, spermicide, foam and vaginal wash before and after engaging in sexual activity.

5. Refusing to work with client who will not use it.

\section{Curative}

1. Take medicines religiously as prescribed by the doctor. 15

2. Subject self for laboratory test.

3. Stop from work if there are signs and symptoms of STIS.

4. Consult the doctor for signs and symptoms of STIs.

5. Visit the doctor immediately after engaging of unsafe sex.

\section{Rehabilitative}

1. Allow self to be confined for infection treatment. 
4. Seek immediate health care if signs and symptoms of STIs 14 reappear.

5. Abstain from engaging in sexual activity during the infection stage of STIs.

Knowledge about STIs and Health Practices among Commercial Sex Workers

The statistical data between knowledge about STIs and health practices reveal no significant relationship between the variables $(\mathrm{r}=-.070, \mathrm{p}=.365 ; \mathrm{r}=.012, \mathrm{p}=.873 ; \mathrm{r}=-.066$, $\mathrm{p}=.801 ; \mathrm{r}=.051, \& \mathrm{p}=.365 ; \mathrm{r}=.830)$. The null hypothesis stating that there was no significant relationship between knowledge about STIs and health practices in terms of promotive, preventive, curative, and rehabilitative was accepted. This means that the knowledge of the respondents about sexually transmitted infections has no influence in all areas of health practice.

Table 5. Relationship between the Knowledge about STIs and Health Practices among Commercial Sex Workers

\begin{tabular}{|c|c|c|c|}
\hline Health Practices & $\begin{array}{l}\text { Knowledge } \\
\text { STIs (r) }\end{array}$ & About p-value & Interpretation \\
\hline Promotive & $\mathrm{r}-.070$ & .365 & Not significant \\
\hline Preventive & r .012 & .873 & Not significant \\
\hline Curative & $\mathrm{r}-.066$ & .801 & Not significant \\
\hline Rehabilitative & r .051 & .830 & Not significant \\
\hline
\end{tabular}

Knowledge about Services Offered by the Hygiene Clinic And Health Practices among Commercial Sex Workers

The results of the relational analysis between the knowledge about the services offered by the hygiene clinic and health practices among commercial sex workers in terms of promotive, preventive, curative, and rehabilitative aspects are presented in Table 6, utilizing the statistical treatment of Pearson product-moment correlation coefficient. The knowledge about the services offered by the hygiene clinic was not significantly correlated with the health practices as evidenced by a Pearson's $r$ values of $r=-.015$ $(\mathrm{p}=.845), \mathrm{r}=.020(\mathrm{p}=.798), \mathrm{r}=.171(\mathrm{p}=.471)$, and $\mathrm{r}=-.564(\mathrm{p}=.010)$. The null hypothesis, therefore, was accepted. This means that their knowledge about the services offered by the hygiene clinic has no influence on their promotive, preventive, curative, and rehabilitative practices.

Table 6. Relationship between the Knowledge about Services Offered by the Hygiene Clinic and Health Practices among Commercial Sex Workers

$\begin{array}{llll}\text { Health Practices } & \begin{array}{l}\text { Knowledge About Services } \\ \text { Offered by the Clinic(r) }\end{array} & \text { p-value } & \text { Interpretation } \\ & & & \\ \text { Promotive } & \text { r }-.015 & .845 & \text { Not significant } \\ \text { Preventive } & \text { r } .020 & .798 & \text { Not significant } \\ \text { Curative } & \text { r.171 } & .471 & \text { Not significant } \\ \text { Rehabilitative } & \text { r }-.564 & .010 & \text { Not significant }\end{array}$




\section{Summary of Findings}

1. The respondents were aware that sexually transmitted infections could be transmitted from one person to another through sexual contact, could be prevented through safe sex practices, and they were aware of the signs and symptoms of sexually transmitted infections.

2. Almost all of them knew that the social hygiene clinic offers free consultation, oneon-one counseling, reading materials, and diagnostic tools are available.

3. The respondents did not have correct promotive health practice wherein more than half of the did not discuss and ask information about sexually transmitted infections, however, a small majority of the respondents had practiced correct preventive measures. Moreover, many of them had better curative and rehabilitative measures in terms of the use and taking of the prescribed medications, allowing self to be confined for infection treatment, and joining support groups in the prevention of sexually transmitted infections.

4. The knowledge about sexually transmitted infections and health practices (promotive, preventive, curative, and rehabilitative) did not yield significant results. The same findings hold true with the knowledge about the services offered by the hygiene clinic and the health practices wherein it did not show significant result.

\section{Conclusion}

The commercial sex workers are knowledgeable about sexually transmitted infections and they are aware of the services provided by the social hygiene clinic. However, their knowledge did not influence their health practices. The findings suggest that a more comprehensive approach which provides a range of services to commercial sex workers, including information dissemination, STIs promotive program, and health education should be sustained and strengthened.

\section{References}

[1] https://www.nichd.nih.gov/health/topics/stds, (2017).

[2] http://www.who.int/reproductivehealth/topics/rtis/en/.

[3] http://www.who.int/reproductivehealth/news/stis-estimates-2015/en.

[4] http://pdf.usaid.gov/pdf_docs/Pnadc488.pdf.

[5] L. Mc Grath-Lone, K. Marsh, G. Hughes and H. Ward, "The sexual health of female sex workers compared with other women in England: analysis of cross-sectional data from genitourinary medicine clinics”, Sex Transm Infect, vol. 90, (2014), pp. 344-350.

[6] M. M. A. Verscheijden P. J. Woestenberg, H. M. Götz, M. G. van Veen, F. D. H. Koedijk and B. H.B. van Benthem, "Sexually transmitted infections among female sex workers tested at STI clinics in the Netherlands, 2006-2013", Emerging Themes in Epidemiology, https://doi.org/10.1186/s12982-0150034-7, vol. 12, no. 12, (2015).

[7] R. Steen and G. Dallabetta, "Sexually transmitted infection control with sex workers: regular screening and presumptive treatment augment efforts to reduce risk and vulnerability", Reproductive Health Matters, doi: 10.1016/S0968-8080(03)02295- X, vol. 11, no. 22, (2003), pp. 74-90.

[8] E.O. Amu and P.T. Adegun, "Awareness and knowledge of sexually transmitted infections among secondary school adolescents in Ado Ekiti, South Western Nigeria", Journal of Sexually Transmitted Diseases, http://dx.doi.org/10.1155/2015/260126, (2015).

[9] G. Blay, "Awareness and knowledge of sexually transmitted infections among female porters in Madina", Masters' Thesis, School of Public Health Science University of Ghana, (2013).

[10] E. Çalıkoğlu, E. Bilgeyerli and Z. Koşan, "Knowledge of brothel workers about sexually transmitted diseases in Erzurum, Turkey", Med Sci Hypotheses, doi: 10.12659/ MSH.903590, vol. 4, (2017), pp. $18-23$.

[11] A. O. Sekoni, O.O. Odukoya, A.T. Onajole and K.A. Odeyemi, "Sexually transmitted infections: prevalence, knowledge and treatment practices among female sex workers in a cosmopolitan city in Nigeria”, Afr J Reprod Health, vol. 1, (2013), pp. 94-102.

[12] M. A. de Matos, K. A. Caetano, D. França, R. Pinheiro, L. de Moraes and S. Teles, "Vulnerability to Sexually Transmitted Infections in women who sell sex on the route of prostitution and sex tourism in 
Central Brazil”, Rev. Latino-Am. Enfermagem, http:// dx.doi.org/10.1590/S0104-11692013000400011, vol. 21,no. 4, (2013).

[13] G.M. Hosain and N. Chatterjee, "Beliefs, sexual behaviours and preventive practices with respect to HIV/AIDS among commercial sex workers in Daulatdia", Bangladesh, Public Health, vol. 119, no. 5, (2005), pp. 371-81.

[14] N. Coma Auli, C. Mejía-Lancheros, A. Berenguera and E. Pujol-Ribera, "Risk perception of sexually transmitted infections and HIV in Nigerian commercial sex workers in Barcelona: a qualitative study", BMJ Open, 5, e006928, doi: 10.1136/bmj-2014-006928, (2015).

[15] A. K. Adeneye, M.A. Mafe, A.A. Adeneye and A.A. Adeiga, "Health-Seeking Behaviour of BrothelBased Female Sex Workers in the Management of Sexually Transmitted Infections in Urban Communities of Ogun State, Nigeria", International Journal of Women's Health Care, vol. 1, no. 1, (2016), pp. 2-6.

\section{Author}

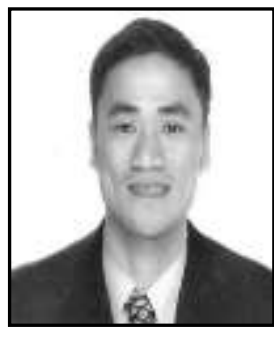

Perry Paul J. Espinosa, $\mathrm{PhD}, \mathrm{RN}$, he is a Professor of Nursing in Woosong College, Daejeon, Republic of Korea. He has extensive nursing undergraduate and graduate teaching experiences. In $\mathrm{PhD}$ programs, he has developed and taught advanced qualitative research inquiry in nursing in University of St. La Salle, Bacolod City, Philippines. He has mentored Masters and $\mathrm{PhD}$ students and a panel member for various thesis and projects. 
International Journal of $u$ - and e- Service, Science and Technology Vol. 11, No.1 (2018) 